\title{
Clostridium Novyi-NT Spores
}

National Cancer Institute

\section{Source}

National Cancer Institute. Clostridium Novyi-NT Spores. NCI Thesaurus. Code C62762.

Spores of the bacterial strain Clostridium novyi-NT, the attenuated oblig ate anaerobic C. novyi, with potential immunostimulating, bacteriolytic, and antineoplastic activities. Upon intravenous administration, Clostridium novyi-NT spores germinate exclusively in hypoxic tissue, such as avascular regions of tumors. Germination results in lysis and destruction of surrounding viable tumor cells. Due to their anaerobic nature, C. novyi-NT spores do not proliferate in oxygenated tumor regions. However, this agent may stimulate the immune system to exert a cellular immune response, resulting in additional killing of tumor cells not lysed by the bacteria, including those in the well-oxygenated tumor area. 